\title{
The Structure of Citizen Bystander Offering Behaviors Immediately After the Boston Marathon Bombing
}

\author{
Nicolas LaLone \\ University of Nebraska at Omaha \\ nlalone@unomaha.edu
}

\author{
Z.O. Toups \\ New Mexico State University \\ z@cs.nmsu.edu
}

\author{
Andrea Tapia \\ Pennsylvania State University \\ atapia@psu.edu
}

\begin{abstract}
In April of 2013, two pressure cooker bombs detonated near the finish line of the Boston Marathon. The resulting crowdsourced criminal investigation has been subject to intense scrutiny. What has not been discussed are the offering behaviors of Twitter users immediately following the detonations. The hashtag \#BostonHelp offers a case study of what emergent, computer-mediated groups offer victims of a crisis event. Through creative appropriation of at-hand technologies (CAAT), this emergent group organized online offering and information about tangible resources on the ground. In this case, \#BostonHelp participants harnessed blogs, social media, Google Forms, and pre-existing services to organize help for those in need. The resulting structure stabilized and became a symbol of the response itself. This case study offers an analysis of the structure created by computermediated crowds. We conclude with a discussion of trying to design, or even detect these behaviors at the start of a crisis response.
\end{abstract}

\section{Introduction}

For over 15 years, researchers in crisis informatics have endeavored to understand how communication technologies function during crisis $[26,32]$. Each crisis or disaster provides a new lens through which to view how people use technology under all manner of duress. Much of this work focuses on how to harness or identify social media in some beneficial way. What is not examined are the ways that those in and around the ground zero of an event foster community by appropriating platforms in ways that were never intended. We contribute a case study that provides context for the offering behaviors of online crowds during a crisis.

On Monday, April 15, 2013, at 2:49 pm, the Boston Marathon was abruptly terminated when two pressure cooker bombs exploded 210 yards $(190 \mathrm{~m})$ from the finish line. These bombs killed three people and injured
264 others. Within hours of the initial event, the US Federal Bureau of Investigation (FBI) called for bystanders to share images and video of the event [19].

It is normal for law enforcement to ask for help from the public through things like wanted posters, tip lines, and neighborhood watch groups. This call for public support asked for the online crowd to help speed up its investigative processes [19]. The parameters of how the crowd processed, shared, and verified their theories have been the subject of repeated academic inquiry but typically center on how those online communities disrupted the FBI's criminal investigation process [5, $12,20,30,36,41]$. That negativity has had an impact on both crowdsourced investigative efforts and the online communities that attempted to assist the FBI in Boston.

As a result, there is a gap of research that focuses on citizen responders engaged in computer-mediated offering behavior or online crowds rendering tangible assistance via computer-mediated means. In this paper, we present a case study of Twitter users who, bounded by the hashtag \#BostonHelp organized offering behaviors of citizen responders during the first 24 hours of the response [4]. This group is not unique.

During each response to a disruptive event like this criminal act or a natural disaster, citizen responders deploy at-hand technologies in creative ways [22, 23, 48]. These technologies not only organize certain kinds of online volunteers, they define their involvement and identity [18]. We call these volunteers citizen responders as they most resemble the citizen scientist in structure and behavior [49]. This technologies that these citizen responders create is creative in its appropriation [7]. Creative appropriation of at-hand technologies or CAATs have implications for numerous aspects of crisis-oriented planning and design.

\section{On Adaptive Structuration}

Our research process was deductive in its origination. We originally sought to describe the behaviors of online residents through the hashtag \#BostonHelp quantitatively through sentiment and 
automated categorization. However, during the research process, we were struck by the ways existing technologies and affordances were appropriated and redeployed within the context of crisis response. As such, we began to explore our data inductively.

We noted that \#BostonHelp contained general similarities to the citizen responder efforts in Hurricane Sandy [48], Hurricane Katrina [35], the California Wildfires [40], and the Sichuan Earthquake [31]. The structures of volunteer and offering within each of these responses seemed to follow a similar path. This structure's consistency resulted in \#BostonHelp being evaluated through the lens of Adaptive Structuration Theory (AST).

AST is useful because it can help explain the varied ways in which individuals respond to similar stimuli, tools, norms, and structures. The theory is concerned with the duality of structure. Put another way, AST is concerned with the process through which members of society manifest the structure of that society. AST is a response to Giddens Structuration Theory [11, 34], which describes the creation and recreation of social structures through behavior, focusing mostly on faithful compliance. In typical structuration, rules and resources are stable through continual use. Over time, rules and resources can be subject to change.

AST, focuses on unfaithful, non-compliant behavior [6] and is particularly useful in examining the introduction of a new technology into social settings. Groups and individuals using information technology create perceptions about the role and utility of a particular piece of technology. In AST, people bring resources to a situation. These resources can include materials, possessions, attributes, expertise, and relationships. Resources, especially during a crisis response, are typically in short supply and are always unequally distributed [1].

To that end, victims within a response area and citizen responders consciously adapt rules and resources to accomplish goals through communication. The adaption, use and creation of beliefs about these technologies give that technology structure. In the case of the Boston Marathon response effort, the need to give and offer aid gave rise to a process that created a structure.

Unfortunately, this process often creates piecemeal tools that are difficult to generalize to other types of disasters. Our term, creative appropriation of at-hand technologies (CAATs), has often been repeated alongside crisis response itself. This a perfect example of Adaptive Structuration in practice and may be a way to generalize and therefore design for this type of behavior.

\section{The Citizen Responder During Crisis}

The use of social media during crisis has been the focus of much research. This research often engages the practice of average citizens reporting on activities "onthe-ground" during a disaster. The data these citizen responders create is increasingly seen as valuable (e.g. $[27,29,38-40,43,47])$. As the potential value of these data has become more evident, the need to make social media data useful to emergency responders has become a strong research focus [42].

However, reliability, quantification of performance, deception, focus of attention, and the translation of reported observations and inferences to respond to crises plague the use of social media within a crisis response [3, 16, 21, 26, 37, 42, 46]. Despite any verifiable test, researchers are still optimistic about the potential of social media. Many pieces of research indicate that issues surrounding those data can be resolved through tweaking affordances or tweaking user behavior [28, 29, 37, 42]. These cases contribute to understanding individuals outside a response helping others in an area in situ.

\subsection{CAAT Or Creative Appropriations of At- Hand Technologies Over Time}

Individual assistance is typically offered immediately during a crisis. Within seconds, bystanders offer their assistance to victims nearest to the Boston Marathon bombing. Organizational assistance comes later in the form of the Red Cross, the Federal Emergency Management Agency (FEMA), and officially recognized responders like local police and fire departments. We have found within \#BostonHelp that creative appropriation of at-hand technologies (CAAT) was an essential aspect of difference. This was not unique to the Boston efforts.

During the 2005 Hurricane Katrina response effort, the Red Cross and FEMA began to deny the donation of goods due to the time and resources it would take to sort and distribute those resources [44]. Individuals were able to organize help in target areas again using at-hand technologies. While these initial offerings during the Katrina response met with some organizational issues, the central practice has seemingly become routine and may have helped speed recovery [35].

In 2008, an earthquake shook China's Sichuan Province. During the recovery, netizens or citizen responders organized rescue and relief efforts via a web forum named Tianya. Action-related posts consisted of groups in the area self-organizing for action [31]. As in previous cases, CAATs allowed citizen responders to organize themselves and generate tangible results. Each 
of these responses occurred through other tools than social media.

By Hurricane Sandy in 2012, social media had overtaken blogging tools and forums as the central organizing areas of citizen responders. Companion pet owners self-organized through Facebook in order to reunite displaced pets with their owners. Administrators of the page regularly posted updates relating successful reunions between pets and owners [48].

In 2014, researchers applied a multilevel model to a corpus of forum posts in order to ascertain how individual and organizational entities interacted during a crisis response [23]. Through their analyses, the researchers found that individuals offered help and maintained order through online environments as individuals or groups of individuals. The researchers attributed this self-organization to the at-hand technologies that afforded them an ability to do so.

CAATs seem to be a defining factor for citizen responders to both organize and affect change for residents impacted by a crisis event. Through these technologies, citizen responders often seem to identify areas that they can help in and under no supervision nor guidance, define their space and provide support. The consistency of CAATs is that whatever products regular Internet residents use to communicate is what is deployed. For those impacted by the Boston Marathon Bombing, this was social media, Google Forms, community blogs, and other at-hand technologies.

\section{Why \#BostonHelp?}

The evolution of \#BostonHelp was shaped by the chaos created by the attack. Cellular service was intermittently down due to overuse and possible connection to bomb detonation. The investigation also halted or delayed airline travel and public transit. Finally, everything near the finish line was confiscated by authorities or destroyed by the bombs. Many of the marathon participants and their families and friends had no identification, no way to pay for things, and nowhere to go or stay. While there were observers near the crime scene that began to deal with immediate needs of those requiring hospitalization, two things became apparent.

First, most of the runners, friends, and families of those runners who were in town for the event would need another night in their hotel room or another place to stay until the area resumed some sense of recovery. Second, in addition to a place to stay, the families of the victims would need to find food, water, and a means through which they could let other loved ones know they had not been injured or needed other types of assistance. These two parameters were responsible for the initial success of \#BostonHelp.
The first tweet that mentions the hashtag \#BostonHelp came from Twitter user @fellinline who simply stated, "If you need a place to crash/water/etc. I am in the south end near back bay. message me. \#BostonHelp." This tweet appeared at 16:18, just 1 hour and 29 minutes after the detonation. Two minutes later another Twitter user proposed that the hashtag \#BostonHelp be used for similar events and began to recruit other users who might have shelter needs.

The Twitter user @mollfrey asked, “proposed hashtag \#BostonHelp for offers of this sort. You know of others?" from these two tweets, individuals began to organize. CAATs were deployed and a structure began to appear for the offering behaviors of the crowd. \#BostonHelp offered assistance to many individuals and groups in need [2]. The lifecycle of the hashtag was brief. While the hashtag showed activity from April 15 to April 25, much of the offering and organizational behavior occurred within the first $24-35$ hours after the bombs exploded.

\section{Method}

There are two methods we deployed for this case study. The first was an ethnography that began with links to external sources of information [24]. This will be discussed in our findings section. The second method was rudimentary categorization and analysis of Twitter activity captured during the Boston Marathon Bombing response using the $\mathrm{R}$ social media package.

For data collection purposes, the tool we deployed gathered all tweets for hashtags \#prayforboston, \#Boston, \#bomb, and the keyword "bombs." Our tool began collecting tweets at around 21:00 on Monday April 15, 2013. Data collection continued until approximately 17:00 Thursday of the following week or April 25, 2013. These criteria resulted in a dataset containing 23,642,905 tweets. Of these tweets, we took a subset of just 4226 categorized tweets. The tweets in this subset consists of every tweet that contains the text \#BostonHelp and over $75 \%$ of those tweets $(\mathrm{N}=3186)$ were made in the first 30 hours of the blasts.

We were interested in offering behavior and first heard of \#BostonHelp through news stories we engaged in previous research $[4,14]$. In order to determine the type of offering behavior found within these selected tweets, we first deployed 3-, 4-, and 5-word $n$-grams. Ngrams are essentially repeated items of 3-, 4-, and 5word phrases. For example, a tweet with, "Food and Water available here" then each of these tweets would count as a 5- word n-gram. "Prayers for Boston" would be a 3-word n-gram.

This method is traditionally used for sentiment analyses as a means to train data (e.g. [10, 17, 25]); 
however, we deployed n-grams in another way. Upon discovery of a repeated $n$-gram, a category of behavior was created. Each category reflected two criteria. First, if an $n$-gram was repeated were these retweets or were different users engaging the same information? Next, each n-gram was compared to the reported activity of the crowd post-event. The result was that each tweet was only assigned one of seven categories.

\subsection{Category Description}

The first category consists of Twitter users offering shelter to victims who remained in Boston. From the first tweet, \#BostonHelp began as a way to connect those with an extra room, bed, or couch to those in need of rest and a place to sleep for the night. Second, prayers and other faith-based sentiment toward those affected by the blasts was common throughout the response. This hashtag captures many tweets that also used the hashtag \#prayforboston, a generalized hashtag used throughout the response.

Support for families came next in priority. These tweets typically offered suggestions about how to connect with members of one's family that were in the Boston area. Next, support for the hashtag itself was prioritized. \#BostonHelp required recruitment and advertising to constantly define its purpose and reify the structures appearing through that use. Offering hashtag support was the next category. These tweets consisted of Twitter users asking how they could help and others suggesting \#BostonHelp.

Food and water tweets consisted of local hotels and local businesses offering free food, water, and company along with quickly organized makeshift shelters. Those that offered technical support were trying to connect victims and residents of the area to online resources and places that had free Wi-Fi or phone charging. Finally, links that linked to outside resources were considered.

\section{Findings}

By slightly adjusting at-hand technologies like Google Forms, the citizen responders of \#BostonHelp offered the crowd places to sleep and eat within hours of the blasts. Please find the frequency of each category below in Table 1. Note that external links and tweets about shelter are the most common tweets with hashtag support being the third most common category.

The primary finding is that in the case of the Boston Marathon Bombing response, the crowd organized offers of shelters under the name of \#BostonHelp. While tweets containing only external links dominate the categories we created, following those links shows that early into the response, this is not the case for the time immediately following the blasts. Many of the links in those tweets were to pages that included an aggregated, verified list of where to give blood, financial support, and within the first day, shelter. Additionally, the tweets that reference Food and Water and Tech Support were typically bundled with offering shelter.

\begin{tabular}{|l|l|c|c|}
\hline \multicolumn{1}{|c|}{ Category } & \multicolumn{1}{|c|}{ Description } & N & \multicolumn{1}{c|}{$\%$} \\
\hline Shelter & Offers place to stay & 814 & 19.26 \\
\hline Religious & $\begin{array}{l}\text { Offers prayers or } \\
\text { mentions God }\end{array}$ & 311 & 7.36 \\
\hline Family support & $\begin{array}{l}\text { Offers support for } \\
\text { families }\end{array}$ & 109 & 2.58 \\
\hline $\begin{array}{l}\text { Hashtag } \\
\text { Support }\end{array}$ & $\begin{array}{l}\text { Suggests a hashtag } \\
\text { to use }\end{array}$ & 591 & 13.98 \\
\hline Food/Water & $\begin{array}{l}\text { Offers food and/or } \\
\text { water }\end{array}$ & 369 & 8.73 \\
\hline Tech Support & $\begin{array}{l}\text { Offers tech help, } \\
\text { charging stations }\end{array}$ & 45 & 1.06 \\
\hline External Links & $\begin{array}{l}\text { Provides an external } \\
\text { link to a resource of } \\
\text { some kind }\end{array}$ & 1987 & 47.02 \\
\hline
\end{tabular}

Table 1. The categories developed out of the dataset of 4,107 \#BostonHelp tweets in order of priority.

We examined the top 25 links that were shared. In Table 2, we show the top 5 linked sources. The most shared link in \#BostonHelp was a CNN article on how to help [4]. This article was a collection of phone numbers, links to blood drives, links to FBI investigation pages, and links to individual donation drives for victims of the blasts. Next, the local newspaper for Boston, The Boston Globe, was linked to in many tweets. This stresses the ability of The Boston Globe to manifest structure as a center for both information and organization.

While no particular article was common among them, linking to Boston.com (a subsidiary site from The Boston Globe) was also common and consisted of over $6 \%$ of all links. This site is important as it represented the primary offering behavior of \#BostonHelp. Additionally, the Bostoninno articles essentially replicated that of Boston.com and The Boston Globe. All of these articles were replicated by the communityoriented blog UniversalHub who was instrumental in giving structure to \#BostonHelp.

Next, the Person Finder from Google was linked. This tool, "helps people reconnect with friends and loved ones in the aftermath of natural and humanitarian disasters" [13]. The other three articles followed that of the first, offering information, where to send monetary donations, how to connect with services on the ground, 
and other types of official ways to offer aid. The rest went to news stories about the investigation.

As we examined the content of these links, we began to consider deploying a brief ethnography. In following this links more systematically, one point of interest was a website called NeighborsforNeighbors.org (NfN). This website, supported by the civic technology ClickforFix asks residents of an area to do one of two things: 1) offer a skill that they would volunteer to others and 2) report on activities that seem to have been overlooked in a geographic area.

\begin{tabular}{|l|c|}
\hline \multicolumn{1}{|c|}{ Link Shared } & \% of all \\
\hline CNN - How to Help & $17.25 \%$ \\
\hline Boston.com & $6.25 \%$ \\
\hline Google Person Finder & $5.05 \%$ \\
\hline Bostoninno article on how to help & $4.75 \%$ \\
\hline Daily Mail Article on How to Help & $4.65 \%$ \\
\hline Bostoninno article - phone numbers & $2.31 \%$ \\
\hline
\end{tabular}

Table 2 - The 5 most shared articles in \#BostonHelp

Interestingly, this site was not represented in our \#bostonhelp subset. However, by following the links, we discovered that it was represented on Facebook and was dedicated to the same offering behaviors. In this case, $N f N$ offers an alternative example of a CAAT and AST not found in our data but that reifies the same structure of offering.

Between NfN, Bostoninno, and The Boston Globe, the primary way that the citizen responders aided and offered help to the victims of the blasts was through organizing places to sleep. These calls for shelter were funneled into two spreadsheets that were created by The Boston Globe but made more available by the community blog - UniversalHub. For those not on Twitter, NfN harnessed the power of the Facebook crowd. What was not clear was whether these offers were ever accepted or even mattered to those on the ground. Despite that unknown, through the hashtag \#BostonHelp it is possible to observe the formation of structure among citizen responders.

\section{Discussion}

\#BostonHelp was formed when residents of Boston began to offer their extra space to those trapped in Boston post-event. Our data displays shows the formation of structure meant to organize offering of space and supplies. The process was as such that some citizen responders offer help to victims and others mimic that offering behavior. The mimicry expands and through the creative appropriation of at-hand tools like social media, blogs, interactive maps and spreadsheets, a movement manifests. \#BostonHelp offer three significant stories to tell about individual level offering behaviors within and throughout crisis response.

First, any event like a crisis response is chaotic and quickly evolving. Evidenced by its consistency, those outside the response efforts but able to observe via social media and news media often want to help. The need to help creates an unaccounted structure for response efforts. Structure is often created by creatively appropriating at-hand technologies (CAATs). This is our second story - the CAATs.

Two Google Forms were created to focus two specific behaviors. The first behavior is, "I have a place to offer." This was created to, "help connect these victims with people who had beds to offer" [45]. The second behavior is, "I need a place to stay." This spreadsheet is particularly interesting because only 32 of nearly 200 entries is actually someone looking for a place to stay. Finally, there is a map-based tool meant to connect those with skill and time to volunteer to those who need help. The creator of this map-based tool adjusted its security restrictions to meet the demand to volunteer resources after the Boston Marathon Bombings.

The final story is about the people or groups behind the CAATs themselves. The local Boston newspaper, The Boston Globe, a community blogging platform called UniversalHub.com, and an individual volunteer and ask for help website called NeighborsforNeighbors.org all creatively deployed their unique skillset through CAATs. The Boston Globe appropriated Google Forms and Google Sheets to organize offering of shelter. Community-centered blogs like UniversalHub used Twitter to foster awareness about the Google Form. NeighborsforNeighbors.org opened their product for the same tasks by supplementing its bandwidth and abilities with the service SeeClickFix. By raising public knowledge of these tools, it follows that those who required help should have been able to find it. However, in nearly every circumstance, offering behavior dominated the activity and asking behaviors remained mostly invisible.

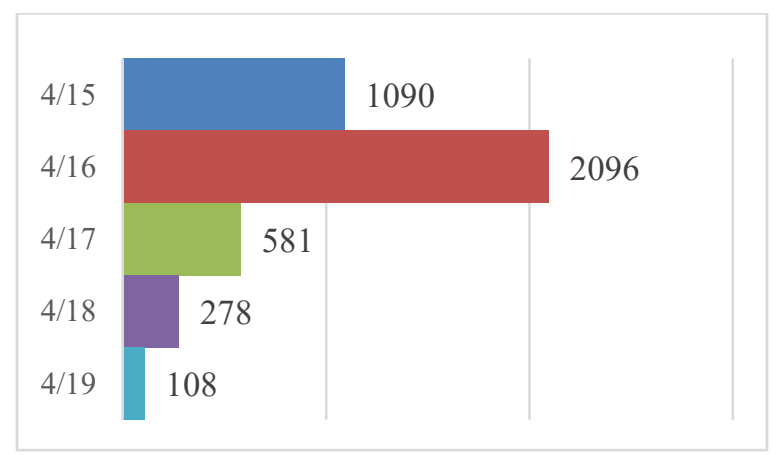

Figure 1 - \#BostonHelp Activity for the first five days 


\subsection{Unaccounted Structures}

In order to understand the context of offering behavior through \#BostonHelp, it is important to note the frequency changes in category by day. The overall frequency of activity is noted in figure 1 . While the most activity is reported on April 16 (2096), the activity on April 15 (1090) accounts for about 7 hours. On April 15, \#BostonHelp activity looked like figure 2 - nearly all offers of shelter. In fact, offers of shelter exceed every other category combined (598 offers of shelter to 492).

Through AST, we understand that people bring perceptions and resources to a particular situation. The perceived need was shelter for those who had nowhere to stay because the Boston Marathon finish line was now a crime scene. The resources each citizen responders had, especially those in Boston itself, was shelter and a social media account. They could also account for new shelters around the area.

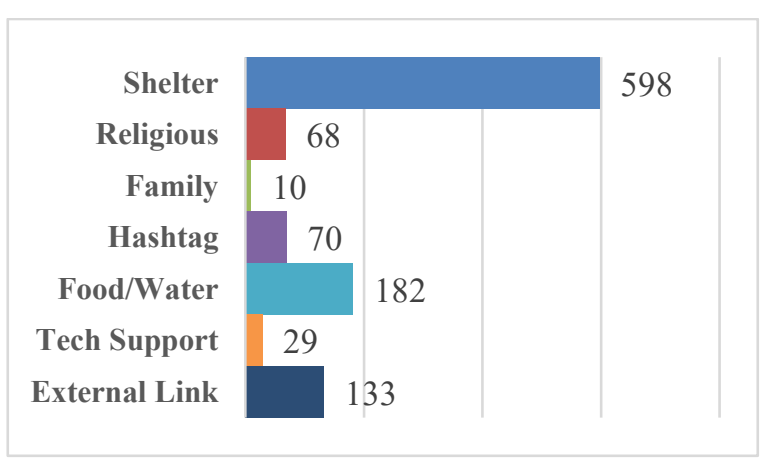

Figure 2 - April 15, 2013 Category Frequency

For example, one popular tweet stated, "In \#boston need help? Make Shift Boston 349 Columbus Ave ready to open doors to anyone: water phone internet etc \#BostonHelp." Other tweets were local businesses offering to aid those who just needed to be around other people. For example, “BOSTON! @ElPelonTaqueria: open wifi place 2 charge cell or just dont want to be alone food and drinks-pay only if you can \#BostonHelp." Other restaurants would follow suit by offering free food and water to both responders and victims - often staying open throughout the night.

Offering behaviors are often overwhelming to official responders. For example, in the Hurricane Katrina and the Fort McMurray Fire reposes, surplus giving often bottlenecked materials that victims needed $([15,33])$. In the first 24 hours after the Boston Marathon Bombing, the offers for shelters declined rapidly. As can be seen between Figure 2 and Figure 3, tweets directly referencing offering behavior declined radically. In its place, external links and hashtag support began to appear. The reason for this decline is not a decline in offering behaviors but in the success of structure creation. The CAATs consolidated and focused offering behaviors - thus creating structure.

\subsection{CAATs and the appearance of structure}

When two pressure cooker bombs exploded near the finish line of the Boston Marathon, the need to give from those who were witnessing from social media increased rapidly. Shortly after the explosions, two Google Forms appeared. There were two different documents, "I have a home to offer" and "I need a place to stay."

Each of these forms fed into a Google Sheet that listed: the time the entry was created, the name of the person filling out the form, a phone number, an email address, the number of people travelling with that person and any other relevant information needed. The documents are still active today though the document offering help has been scrubbed of private information like name and contact information.

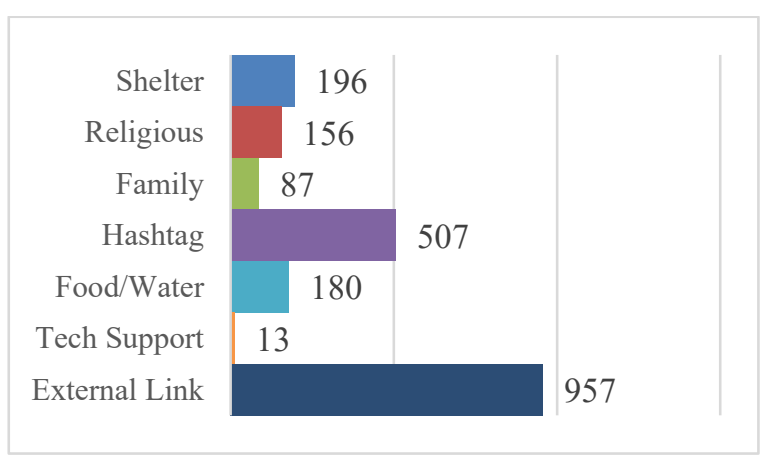

Figure 3 - April 16, 2013 Category Frequency

The structure offered by these documents was reified quickly. Within the Twitter data, calls offering shelter were quickly replaced by calls to go to the Google Forms: RT @kingdomofwench: If you are stranded in Boston \&amp; need a place to stay here is a list of people offering: https://t.co/pfQkJJ3lpv \#BostonHelp \#helpers. Hundreds of other tweets and retweets took the place of individual offering behavior. With the creation of a consolidated, streamlined way to offer shelter, other organizations began to follow suit.

Corporate offering behaviors also began to appear. Airbnb began to offer rooms in Boston without a fee. This service, which allows its users to list rooms for rent in their home, or extra apartments they may have purchased, organized free rooms and apartments in the Boston area. Airlines also began to offer travel waivers for those people trying to leave Boston due to the chaotic nature of cancelled flights, injuries, and loss of identification.

Though never mentioned in the hashtag directly, many of the links shared by those on \#BostonHelp 
contained links to other services like the Google Forms. Additionally, Facebook groups like, "Affected by the explosions at the Boston Marathon? We're here to help" also began to fill the structures created by the blasts. On Facebook and in lists of helpful tools for victims and citizen responders pointed to a website called NeighborsforNeighbors (NfN). NfN allows residents of Boston to volunteer their abilities or request the abilities of others. This particular service mimicked the Google Forms removal of security to display the desire of citizen responders to help those impacted by the blasts.

Many aspects of the structures that were needed within the response were indicative of the technologies that were needed. The technologies deployed bridged tangible need with digital offering. Who created those technologies is of particular interest. At first blush, it seems as though all agents necessary to create this structure were in the right place at the right time. However, there is a more complicated context than that.

\subsection{Agents of Structuration}

Boston is a large metropolitan region with several major colleges, a large newspaper, professional sports teams, and myriad other resources. In addition, there were thousands of people near the finish line of this century old marathon with their cameras already out trying to take pictures of runners as they crossed the finish line. The early chaos of the initial response is indicative of the issues of having too much information too quickly.

The confusion continued when citizen responders began to offer runners their own resources, their own shelters, their own food, and more. In order to understand the structures that are evident through \#BostonHelp, it is necessary to describe the context of the agents who deployed these technologies. When the explosions occurred, people began to turn to news media, social media, and other forms of communication that were focused on the city.

The Boston Globe was first to start reporting in the area. As information came in, The Boston Globe created information pages for those who wanted to help. These pages focused on where to give blood; if giving blood was needed given current supply; where to donate money to support victims; which families needed the most support; and other information as it became available. As a result, The Boston Globe and its subsidiary Boston.com faced a significant increase in server traffic [8].

While The Boston Globe adjusted for this server traffic and deployed their reporters to learn more about what was happening in and around the city, they saw citizen responders engage in offering behavior. This is nothing new as newspapers are often a center for posting ads that indicate offering behaviors like "For Sale" or "Help Wanted" classified advertisements. While services like Craigslist have partially replaced classified ads, newspapers still provide these services when available.

In mimesis of classified advertisements, The Boston Globe deployed Google Forms. By using Google, they could re-direct those interested in offering their own resources to a place that did not take more of their strained server load. The Google Forms were created and appeared on Boston.com but seemed to gain more interactivity once they went to Twitter. In our data, the links to the Google Form and Google Sheet appeared through a post by the owner of the Boston community blog UniversalHub, "Heres the link to sign up to host runners in Boston [link removed] \#BostonHelp.'

The links to the spreadsheets were also posted on the blog itself. As a result, The Boston Globe had essentially used their skillset as a place to organize information and UniversalHub deployed their skillset to raise awareness about this new resource. This resulted in approximately 6000 individual pieces of offering from within Boston itself [45]. This service was not the only structure that was created during the response. While The Boston Globe and UniversalHub raised awareness about the services on Google Forms, another entity was raising awareness about a different service through Facebook.

The website NeighborsforNeighbors.org (NfN) also creatively appropriated their own service and deployed it in a way similar to the Google Forms. NfN typically offers their service in an extremely secure manner. First, an $N f N$ user must declare they are a resident of Boston by zip code as they sign up for the service. In order to expedite offering during the bombings, many of these security restrictions were waived. In total, over 700 posts were made on the $N f N$ website. This number is significant; however, these requests followed that of the others-all offers to help, very few requests for help.

Throughout the Boston Marathon response present via \#BostonHelp, The Boston Globe, NeighborsforNeighbors and the community blogging platform UniversalHub stand out as agents of structure. Unfortunately, it is unclear if any of these services truly helped any victims of the Boston Marathon Bombing. While over 6000 and over 700 offers were created by citizen responders on Google Forms and NfN respectively, around 30 requests for help remain visible on any of the tools that were advertised.

Many aspects of the structures that were needed within the crisis were indicative what would become the technologies deployed to bridge need with digital offering. The Boston Globe deployed what amounted to 
a classified service using Google's servers to handle the load. UniversalHub took to social media to present these services and garner support through their work. Finally, NeighborsforNeighbors harnessed the popularity of their service by losing all security restrictions. Through the lens of AST, we see resources being deployed that reified the offering behaviors of citizen responders.

\section{Conclusion}

Through the lens of AST, we focused on the offering behaviors of citizen responders on Twitter. \#BostonHelp showed how technology reifies citizen responder offering about makeshift shelters and the location of resources. The structure was produced by two creatively appropriated technologies: Google Forms and a Google Maps-oriented volunteer service. Citizen Responders fostered this structure through use paired with media exposure and consistent broadcasting of those links on Twitter and Facebook.

These small groups often seem to go undetected. We hope that assembling a detailed description of the offering behaviors of \#BostonHelp will aid in detecting them during a response rather than after. Of future interest is that it is unclear if these behaviors actually provide help to victims.

Offering behavior accounted for in over 7000 entries between 2 different CAATs while asking behavior only accounted for 30. Despite the disparity, the structures created by these CAATs were beneficial to the spirit of the response itself. Some called the resulting spreadsheets the embodiment of empathy for the victims of the blasts [9].

\subsection{Designing for Emergence}

The citizen responders of \#BostonHelp organized themselves into a recognizable structure. Through Twitter the deployment of CAATs that bridged The Boston Globe, Boston.com, \#BostonHelp, UniversalHub, Twitter, and the people of Boston who had space to give. These technologies gave \#BostonHelp and offering behavior structure. Through that structure, the CAATs came to embody the empathy of the region.

Traditionally, emergency planners and managers try have sought to plan for these sorts of groups yet have continually failed [18]. The way planning occurs is by instituting training and drill procedures so that when a warning is given; instant, unthinking action is taken. Unfortunately, these actions and drills are traditionally focused on those people in an area affected by some sort of crisis event, not for those groups on social media.
Most discussion about social media use during a response concerns a duality - social media use and official response. For example, "Tweaking" the Tweet through specialized information retrieval hashtags can bridge social media use and official response. Or, "tweaking" users of social media can provide useful information to emergency responders $[38,39]$. Through \#BostonHelp, we see that self-motivated, self-propelled users of social media know more about the local area than official responders do.

Each event shows that an individual or group fills in a structure that has not been defined until their actions identified it. These individuals are varied in their skillset, intent, and comprehension of the traditional methods of crisis response. We believe that allowing these things to occur on their own is neither controllable, nor plannable. CAATs appear without any previously defined or noticeable structure existing beforehand.

What can be accounted for is that these individuals, especially citizen responders on social media (generally, not just on Twitter) will tend to focus on organizing citizen responder offering. This typically takes the form of shelter if the crisis requires it, food, water, and other resources if needed. The act of design for emergence is not about the actions of these individuals, but about the context of their actions - for example, in the Boston Marathon Bombing, the shelter needs of suddenly stranded marathon runners.

Complex computational methods of event detection typically do not find them until after the event. However, basic frequencies of hashtags, posts offering some type of assistance, and posts offering any sort of "use" are indicative of structures being created. The window for these structures is exceedingly small yet their data gathering and resource inventory is performed much more quickly. Instead of attempting to control these emergent groups, we suggest detecting and observing.

\section{References}

[1] Daniel P Aldrich. 2012. Building resilience: Social capital in post-disaster recovery. University of Chicago Press.

[2] Harriet Arkell. 2013. Acts of kindness amidst the terror: How strangers helped each other as the bombs went off - and now what YOU can do to help DailyMail.com, Online.

[3] Sitaram Asur and Bernardo A Huberman. 2010. Predicting the future with social media. in Web Intelligence and Intelligent Agent Technology (WIIAT), 2010 IEEE/WIC/ACM International Conference on, IEEE, 492-499. 
[4] Rebecca Angel Baer and Katie Walmsley. 2013. Tragedy in Boston: How to help. CNN ed.

[5] Christopher A Cassa, Rumi Chunara, Kenneth Mandl and John S Brownstein. 2013. Twitter as a sentinel in emergency situations: lessons from the Boston marathon explosions. PLoS currents, 5.

[6] Gerardine DeSanctis and Marshall Scott Poole. 1994. Capturing the complexity in advanced technology use: Adaptive structuration theory. Organization science, 5 (2). 121-147.

[7] Paul Dourish. 2003. The appropriation of interactive technologies: Some lessons from placeless documents. Computer Supported Cooperative Work (CSCW), 12 (4). 465-490.

[8] Seth Fiegerman. 2013. How 'The Boston Globe' Covered Its Own City Under Siege, Mashable, Mashable.

[9] Megan Garber. 2013. Boston and the Kindness of Google Docs Empathy, in the guise of a spreadsheet The Atlantic.

[10] M Ghiassi, J Skinner and D Zimbra. 2013. Twitter brand sentiment analysis: A hybrid system using n-gram analysis and dynamic artificial neural network. Expert Systems with applications, 40 (16). 6266-6282.

[11] Anthony Giddens. 1984. The constitution of society: Outline of the theory of structuration. Univ of California Press.

[12] Rebekah Dawn Giordano. 2014. Tweeting the Boston Marathon Bombings: A Case Study of Twitter Content in the Immediate Aftermath of a Major Event Advertising, University of Nebraska, Lincoln, Nebraska, 36.

[13] Google. 2013. Google Person Finder - Boston Explosions Google Person Finder, Google.org, Google.org, Google Person Finder for Marathon Bombings.

[14] HLN. 2013. \#BostonHelp: What to do, how you can help Headline News, HLN.

[15] Tristin Hopper. 2016. After Fort McMurray fire, Alberta copes with 'second disaster' of misguided donations National Post.

[16] Amanda Lee Hughes and Leysia Palen. 2009. Twitter adoption and use in mass convergence and emergency events. International Journal of Emergency Management, 6 (3). 248-260.

[17] Efthymios Kouloumpis, Theresa Wilson and Johanna D Moore. 2011. Twitter sentiment analysis: The good the bad and the omg! Icwsm, 11. 538-541.
[18] Nicolas LaLone, Jess Kropczynski and Andrea Tapia. 2018. The Symbiotic Relationship of Crisis Response Professionals and Enthusiasts as Demonstrated by Reddit's User-Interface Over Time. in Proceedings of the 15th Information Systems for Crisis Response and Management Conference, Rochester, NY.

[19] Declan McCullagh. 2013. FBI seeks crowdsourcing help in Boston bombing case: ID these two men! CNET.

[20] Megan M Mcintyre. 2015. Relational Agency, Networked Technology, and the Social Media Aftermath of the Boston Marathon Bombing.

[21] Marcelo Mendoza, Barbara Poblete and Carlos Castillo. 2010. Twitter Under Crisis: Can we trust what we RT? in Proceedings of the first workshop on social media analytics, ACM, 71-79.

[22] Robert Munro. 2010. Crowdsourced translation for emergency response in Haiti: the global collaboration of local knowledge. Translation, A.W.o.C.C.f. ed.

[23] Ning Nan and Yong Lu. 2014. Harnessing the Power of Self-Organization in an Online Community During Organizational Crisis. Mis Quarterly, 38 (4). 1135-1157.

[24] B Narayan, BA Talip, JW Watson and SL Edwards. 2016. Digital Ethnography as a Way to Explore Information Grounds on Twitter. Qualitative and Quantitative Methods in Libraries.

[25] Alexander Pak and Patrick Paroubek. 2010. Twitter as a Corpus for Sentiment Analysis and Opinion Mining. in LREc, 1320-1326.

[26] Leysia Palen and Kenneth M Anderson. 2016. Crisis informatics - New data for extraordinary times. Science, 353 (6296). 224-225.

[27] Leysia Palen and Sarah Vieweg. 2008. The emergence of online widescale interaction in unexpected events: assistance, alliance \& retreat. in Proceedings of the 2008 ACM conference on Computer supported cooperative work, ACM, 117-126.

[28] Leysia Palen, Sarah Vieweg and Kenneth Mark Anderson. 2010. Supporting "everyday analysts" in safety-and time-critical situations. The Information Society, 27 (1). 52-62.

[29] Leysia Palen, Sarah Vieweg, Jeannette Sutton, Sophia B Liu and Amanda L Hughes. 2007. Crisis informatics: Studying crisis in a networked world.". in Proceedings of the Third International Conference on E-Social Science. 
[30] Liza Potts and Angela Harrison. 2013. Interfaces as rhetorical constructions: reddit and 4chan during the boston marathon bombings. in Proceedings of the 31st ACM international conference on Design of communication, ACM, 143-150.

[31] Yan Qu, Philip Fei Wu and Xiaoqing Wang. 2009. Online community response to major disaster: A study of Tianya forum in the 2008 Sichuan earthquake. in System Sciences, 2009. HICSS'09. 42nd Hawaii International Conference on, IEEE, 1-11.

[32] Christian Reuter and Marc-André Kaufhold. 2018. Fifteen years of social media in emergencies: a retrospective review and future directions for crisis informatics. Journal of Contingencies and Crisis Management, 26 (1). 41-57.

[33] Tracey E Rizzuto and Laura K Maloney. 2008. Organizing chaos: Crisis management in the wake of Hurricane Katrina. Professional Psychology: Research and Practice, 39 (1). 77.

[34] Jeremy Rose and Rens Scheepers. 2001. Structuration Theory and Information System Development - Frameworks for Practice. in 9th European Conference on Information Systems, Bled, Slovenia, 217-231.

[35] Irina Shklovski, Moira Burke, Sara Kiesler and Robert Kraut. 2010. Technology adoption and use in the aftermath of Hurricane Katrina in New Orleans. American Behavioral Scientist, 53 (8). 1228-1246.

[36] Kate Starbird, Jim Maddock, Mania Orand, Peg Achterman and Robert M Mason. 2014. Rumors, false flags, and digital vigilantes: Misinformation on twitter after the 2013 boston marathon bombing. iConference 2014 Proceedings.

[37] Kate Starbird and Leysia Palen. 2010. Pass it on?: Retweeting in mass emergency. International Community on Information Systems for Crisis Response and Management.

[38] Kate Starbird, Leysia Palen, Sophia B Liu, Sarah Vieweg, Amanda Hughes, Aaron Schram, Kenneth Mark Anderson, Mossaab Bagdouri, Joanne White and Casey McTaggart. 2012. Promoting structured data in citizen communications during disaster response: an account of strategies for diffusion of the "tweak the tweet" syntax. Crisis information management: Communication and technologies. 43-63.

[39] Kate Starbird and Jeannie Stamberger. 2010. Tweak the Tweet: Leveraging Microblogging Proliferation with a Prescriptive Syntax to Support Citizen Reporting. in Proceedings of the 7th International ISCRAM Conference-Seattle.
[40] Jeannette Sutton, Leysia Palen and Irina Shklovski. 2008. Backchannels on the front lines: Emergent uses of social media in the 2007 southern California wildfires. in Proceedings of the 5th International ISCRAM Conference, Washington, DC, 624-632.

[41] Andrea H Tapia, Nicolas LaLone and Hyun-Woo Kim. 2014. Run amok: group crowd participation in identifying the bomb and bomber from the boston marathon bombing. Proceedings of the 11th ISCRAM.

[42] Andrea H Tapia, Kathleen A Moore and Nichloas J Johnson. 2013. Beyond the trustworthy tweet: A deeper understanding of microblogged data use by disaster response and humanitarian relief organizations. in Proceedings of the 10th International ISCRAM Conference, 770-778.

[43] Teun Terpstra, A de Vries, R Stronkman and GL Paradies. 2012. Towards a realtime Twitter analysis during crises for operational crisis management. Simon Fraser University.

[44] Cristen Torrey, Moira Burke, Matthew Lee, Anind Dey, Susan Fussell and Sara Kiesler. 2007. Connected giving: Ordinary people coordinating disaster relief on the Internet. in System Sciences, 2007. HICSS 2007. 40th Annual Hawaii International Conference on, IEEE, 179a-179a.

[45] Andrew Tran. Thousands offer homes to stranded Boston marathoners.

[46] Sarah Vieweg. 2010. Microblogged contributions to the emergency arena: Discovery, interpretation and implications. Computer Supported Collaborative Work. 515-516.

[47] Sarah Vieweg, Leysia Palen, Sophia B Liu, Amanda L Hughes and Jeannette Sutton. 2008. Collective intelligence in disaster: An examination of the phenomenon in the aftermath of the 2007 Virginia Tech shootings. in Proceedings of the Information Systems for Crisis Response and Management Conference (ISCRAM).

[48] Joanne I White, Leysia Palen and Kenneth M Anderson. 2014. Digital mobilization in disaster response: the work \& self-organization of on-line pet advocates in response to hurricane sandy. in Proceedings of the 17th ACM conference on Computer supported cooperative work \& social computing, ACM, 866-876.

[49] Andrea Wiggins and Kevin Crowston. 2010. Developing a conceptual model of virtual organisations for citizen science. International Journal of Organisational Design and Engineering, 1 (1). 148162. 